\title{
Hyperketonemia: Clinical features and diagnosis of Diabetic Ketoacidosis
}

\section{Reshad Hassannezhad}

Department of Endocrinology,USA.

Corresponding Author : Reshad Hassannezhad, Department of Endocrinology. Email: rashad.chem@gmail.com

Received date: September 19,2018;Accepted date : October 02,2018; Published date: October 08,2018.

Citation for this Article : Reshad Hassannezhad, Hyperketonemia: Clinical features and diagnosis of Diabetic Ketoacidosis. J. Endocrinology and Disorders. Doi: 10.31579/2640-1045/033

Copyright : (C) 2018 Reshad Hassannezhad .This is an open-access article distributed under the terms of the Creative Commons Attribution License, which permits unrestricted use, distribution, and reproduction in any medium, provided the original author and source are credited.

\section{Abstract}

Diets that boost ketone production are increasingly used for treating several neurological disorders. Elevation in ketones in most cases is considered favorable, as they provide energy and are efficient in fueling the body's energy needs.

Several physiological and pathological triggers, such as fasting, ketogenic diet, and diabetes cause an accumulation and elevation of circulating ketones. Complications of the brain, kidney, liver, and microvasculature were found to be elevated in diabetic patients who had elevated ketones compared to those diabetics with normal ketone levels.

Diabetic ketoacidosis is an acute metabolic complication of diabetes characterized by hyperglycemia, hyperketonemia, and metabolic acidosis. Hyperglycemia causes an osmotic diuresis with significant fluid and electrolyte loss. DKA occurs mostly in type 1 diabetes mellitus (DM). It causes nausea, vomiting, and abdominal pain and can progress to cerebral edema, coma, and death. DKA is diagnosed by detection of hyperketonemia and anion gap metabolic acidosis in the presence of hyperglycemia. Treatment involves volume expansion, insulin replacement, and prevention of hypokalemia.

Diabetic ketoacidosis (DKA) is a rare yet potentially fatal hyperglycemic crisis that can occur in patients with both type 1 and 2 diabetes mellitus. Due to its increasing incidence and economic impact related to the treatment and associated morbidity, effective management and prevention is key. Elements of management include making the appropriate diagnosis using current laboratory tools and clinical criteria and coordinating fluid resuscitation, insulin therapy, and electrolyte replacement through feedback obtained from timely patient monitoring and knowledge of resolution criteria. In addition, awareness of special populations such as patients with renal disease presenting with DKA is important. During the DKA therapy, complications may arise and appropriate strategies to prevent these complications are required. DKA prevention strategies including patient and provider education are important. This review aims to provide a brief overview of DKA from its pathophysiology to clinical presentation with in depth focus on up-to-date therapeutic management

Keywords

DKA Treatment, Insulin, Prevention.

\section{Introduction}

\section{Pathophysiology}

Diabetic ketoacidosis arises because of a lack of insulin in the body. The lack of insulin and corresponding elevation of glucagon leads to increased release of glucose by the liver (a process that is normally suppressed by insulin) from glycogen via glycogenolysis and also through gluconeogenesis. High glucose levels spill over into the urine, taking water and solutes (such as sodium and potassium) along with it in a process known as osmotic diuresis. This leads to polyuria, dehydration, and polydipsia. The absence of insulin also leads to the release of free fatty acids from adipose tissue (lipolysis), which are converted through a process called beta oxidation, again in the liver, into ketone bodies (acetoacetate and $\beta$-hydroxybutyrate). $\beta$ Hydroxybutyrate can serve as an energy source in the absence of insulin-mediated glucose delivery, and is a protective mechanism in case of starvation. The ketone bodies, however, have a low pKa and therefore turn the blood acidic (metabolic acidosis). The body initially buffers the change with the bicarbonate buffering system, but this system is quickly overwhelmed and other mechanisms must work to compensate for the acidosis.

In various situations such as infection, insulin demands rise but are not matched by the failing pancreas.
Blood sugars rise, dehydration ensues, and resistance to the normal effects of insulin increases further by way of a vicious circle. As a result of the above mechanisms, the average adult with DKA has a total body water shortage of about 6 liters (or $100 \mathrm{~mL} / \mathrm{kg}$ ), in addition to substantial shortages in sodium, potassium, chloride, phosphate, magnesium and calcium. Glucose levels usually exceed $13.8 \mathrm{mmol} / \mathrm{L}$ or $250 \mathrm{mg} / \mathrm{dL}$.

\section{Materials And Methods}

Diagnosis of DKA followed the criteria of the ISPAD. Blood samples were taken on admission for clinical chemistry and full blood count. An acid-base status was assessed by capillary blood gas analysis. Urine ketones were measured by reflection photometry Siemens, Germany) with a detection limit of $15 \mathrm{mg} / \mathrm{dl}$.

Patients were treated according to a written in-house protocol which followed the ISPAD consensus guidelines 2000 and its updates:

a)Fluid replacement:Intravenous fluid substitution was started with normal saline solution $(\mathrm{NaCl} 0.9 \%)$. When blood glucose level fell below $250 \mathrm{mg} / \mathrm{dl}$, it was changed to half-electrolyte solution $(\mathrm{NaCl} 0.45 \%$ / Glucose $5 \%$ ). 
b) Insulin administration: A dilution of regular insulin was administered intravenously at $1 \mathrm{IU} / \mathrm{ml}$ by an infusion pump. The initial substitution dose varied between 0.05 and $0.1 \mathrm{IU} / \mathrm{kg} / \mathrm{h}$. A reduction in blood glucose between 50 and $100 \mathrm{mg} / \mathrm{dl} / \mathrm{h}$ was achieved by adapting insulin and fluid infusion rates. Intravenous insulin application was switched to subcutaneous insulin application once ketoacidosisresolved $(\mathrm{pH} \geq 7.3)$ and the patients returned to a stable clinical condition.

c) Potassium replacement: Potassium was administered from the beginning of insulin treatment when oliguria and hyperkalemia were excluded. We started an overall substitution of 2 to $3 \mathrm{mmol} / \mathrm{kg} / 24 \mathrm{~h}$. Potassium substitution was administered continuously by a separate infusion pump,which allowed adjustment of replacement independently of the fluid replacement. The substitution dose was adjusted hourly depending on the serum potassium levels.

d) Correction of acidosis: Correction of acidosis was performed by substitution of insulin and fluid alone. The use of sodium bicarbonate was considered only in case of decreased cardiac contractility or life-threatening hyperkalemia. The blood $\mathrm{pH}$ level did not serve as criteria for the use of bicarbonate.

e) Monitoring: Vital signs and ECG were monitored continuously. Capillary blood gases as well as blood glucose and electrolytes were initially checked every hour.

\section{Treatment}

The therapeutic goals of DKA management include optimization of 1) volume status; 2) hyperglycemia and ketoacidosis; 3) electrolyte abnormalities; and 4) potential precipitating factors. The majority of patients with DKA present to the emergency room. Therefore, emergency physicians should initiate the management of hyperglycemic crisis while a physical examination is performed, basic metabolic parameters are obtained, and final diagnosis is made. Several important steps should be followed in the early stages of DKA management:

1. collect blood for metabolic profile before initiation of intravenous fluids;

2. infuse $1 \mathrm{~L}$ of $0.9 \%$ sodium chloride over 1 hour after drawing initial blood samples;

3. ensure potassium level of $>3.3 \mathrm{mEq} / \mathrm{L}$ before initiation of insulin therapy (supplement potassium intravenously if needed);

4. Initiate insulin therapy only when steps 1-3 are executed.

\section{Correction of hyperglycemia and Acidosis}

Hyperglycemia is corrected by giving regular insulin $0.1 \mathrm{unit} / \mathrm{kg}$ IV bolus initially, followed by continuous IV infusion of $0.1 \mathrm{unit} / \mathrm{kg} / \mathrm{h}$ in $0.9 \%$ saline solution. Insulin should be withheld until serum potassium $i s \geq 3.3 \mathrm{mEq} / \mathrm{L}$ ( Hyperosmolar Hyperglycemic State (HHS) : Treatment). Insulin adsorption onto IV tubing can lead to inconsistent effects, which can be minimized by preflushing the IV tubing with insulin solution. If plasma glucose does not fall by 50 to $75 \mathrm{mg} / \mathrm{dL}$ ( 2.8 to $4.2 \mathrm{mmol} / \mathrm{L}$ ) in the first hour, insulin doses should be doubled. Children should be given a continuous IV insulin infusion of 0.1 unit $/ \mathrm{kg} / \mathrm{h}$ or higher with or without a bolus.

Ketones should begin to clear within hours if insulin is given in sufficient doses. However, clearance of ketones may appear to lag because of conversion of beta-hydroxybutyrate to acetoacetate (which is the "ketone" measured in most hospital laboratories) as acidosis resolves. Serum $\mathrm{pH}$ and bicarbonate levels should also quickly improve, but restoration of a normal serum bicarbonate level may take $24 \mathrm{~h}$. Rapid correction of $\mathrm{pH}$ by bicarbonate administration may be considered if $\mathrm{pH}$ remains $<7$ after about an hour of initial fluid resuscitation, but bicarbonate is associated with development of acute cerebral edema (primarily in children) and should not be used routinely.
If used, only modest $\mathrm{pH}$ elevation should be attempted (target $\mathrm{pH}$ of about 7.1), with doses of 50 to $100 \mathrm{mEq}$ over 30 to 60

$\mathrm{min}$, followed by repeat measurement of arterial $\mathrm{pH}$ and serum potassium.

\section{Hypokalemia prevention}

Hypokalemia prevention requires replacement of 20 to $30 \mathrm{mEq}$ potassium in each liter of IV fluid to keep serum potassium between 4 and $5 \mathrm{mEq} / \mathrm{L}$. If serum potassium is $<3.3 \mathrm{mEq} / \mathrm{L}$, insulin should be withheld and potassium given at $40 \mathrm{mEq} / \mathrm{h}$ until serum potassium is $\geq 3.3 \mathrm{mEq} / \mathrm{L}$; if serum potassium is $>5 \mathrm{mEq} / \mathrm{L}$, Potassium supplementation can be withheld.

Initially normal or elevated serum potassium measurements may reflect shifts from intracellular stores in response to acidemia and belie the true potassium deficits that almost all patients with diabetic ketoacidosis have. Insulin replacement rapidly shifts potassium into cells, so levels should be checked hourly or every other hour in the initial stages of treatment.

\section{Complications}

Hypoglycemia is the most frequent complication of DKA and can be prevented by timely adjustment of insulin dose and frequent monitoring of blood glucose levels. Hypoglycemia is defined as any blood glucose level below $70 \mathrm{mg} / \mathrm{dL}$. If DKA is not resolved and blood glucose level is below $200-250 \mathrm{mg} / \mathrm{dL}$, decrease in insulin infusion rate and/or addition of $5 \%$ or $10 \%$ dextrose to current intravenous fluids can be implemented. When DKA is resolved, strategies to manage hypoglycemia will depend on whether or not the patient is able to maintain oral intake. For patients who are able to drink or eat, ingestion of 15-20 g of carbohydrates, eg, four glucose tablets, 6 ounces of orange or apple juice, or "regular" soda, is advised. In patients who are nil by mouth, unable to swallow, or have an altered level of consciousness, administration of $25 \mathrm{~mL}$ of $50 \%$ dextrose intravenously or $1 \mathrm{mg}$ glucagon intramuscularly, if no intravenous access is present, is recommended. Blood glucose should be rechecked after 15 minutes; only if the glucose level is $<70 \mathrm{mg} / \mathrm{dL}$ should the above steps be repeated.

Non-anion gap hyperchloremic metabolic acidosis frequently develops during DKA treatment and is believed to occur due to urinary losses of ketoanions, which are needed for bicarbonate regeneration, and preferential reabsorption of chloride in proximal renal tubule secondary to intensive administration of chloride-containing fluids. This acidosis usually resolves spontaneously in a few days and should not affect the treatment course. Cerebral edema due to rapid reduction in serum osmolality has been reported in young adult patients. This condition is manifested by appearance of headache, lethargy, papillary changes, or seizures, with mortality rates reaching $70 \%$. Mannitol infusion and mechanical ventilation should be used to treat this condition. Rhabdomyolysis is another possible complication due to hyperosmolality and hypoperfusion. Pulmonary edema can develop from excessive fluid replacement in patients with chronic kidney disease or congestive heart failure.

\section{Perioperative management of DKA}

If a surgical cause is identified, senior multidisciplinary review to discuss the optimal timing of surgery is required. It is also important to try and ensure that the clinical picture of an 'acute abdomen' is not secondary to the DKA in order to prevent needless surgery. The Royal College of Surgeons (RCS) document 'Emergency Surgery, Standards for unscheduled surgical care' provides a useful framework that promotes timely surgery but allows time for accurate diagnosis, initial treatment, and resuscitation.

Table 1 is an example of a typical fluid replacement regimen for a previously well $70 \mathrm{~kg}$ adult. However, the exact rate of infusion should be formulated after clinical assessment of the individual patient. If the patient is shocked, the patient should receive an initial bolus of $500 \mathrm{ml}$ over $<15$ min, and further fluid boluses dependent on clinical re-assessment. 
Results

Table 1

Typical fluid replacement regimen for a previously well $70 \mathrm{~kg}$ adult on the general ward.

\begin{tabular}{|l|l|l|}
\hline $\begin{array}{l}\text { Fluid } \\
\text { number }\end{array}$ & Fluid Rate & \\
\hline Initial bag & 1 litre $0.9 \%$ saline $1000 \mathrm{ml} \mathrm{h}-1$ & \\
\hline 2nd bag & $\begin{array}{l}1 \text { litre } 0.9 \% \text { saline with premixed } \\
\text { potassium chloride }\end{array}$ & $500 \mathrm{ml} \mathrm{h}-1$ \\
\hline 3rd bag & $\begin{array}{l}1 \text { litre } 0.9 \% \text { saline with premixed } \\
\text { potassium chloride }\end{array}$ & $500 \mathrm{ml} \mathrm{h}-1$ \\
\hline 4th bag & $\begin{array}{l}1 \text { litre } 0.9 \% \text { saline with premixed } \\
\text { potassium chloride }\end{array}$ & $250 \mathrm{ml} \mathrm{h}-1$ \\
\hline 5th bag & $\begin{array}{l}1 \text { litre } 0.9 \% \text { saline with premixed } \\
\text { potassium chloride }\end{array}$ & $250 \mathrm{ml} \mathrm{h}-1$ \\
\hline 6th bag & $\begin{array}{l}1 \text { litre } 0.9 \% \text { saline with premixed } \\
\text { potassium chloride }\end{array}$ & $150 \mathrm{ml} \mathrm{h}-1$ \\
\hline Further fluid & $\begin{array}{l}1 \text { litre } 0.9 \% \text { saline with premixed } \\
\text { potassium chloride } \\
\text { assessment }\end{array}$ & Clinical \\
\hline $\begin{array}{l}\text { With regular } \\
\text { re-assessment }\end{array}$ & & \\
\hline
\end{tabular}

\section{Monitoring and replacement of electrolytes}

Initial serum potassium may be normal, raised or low in DKA. However, there is a total body potassium deficit. Potassium loss is caused by a shift from the intracellular to extracellular space in exchange for hydrogen ions which accumulate in acidosis. The extracellular potassium is then lost through osmotic diuresis.

The initial litre of fluid should not have potassium added. Provided the serum potassium is $<5.5 \mathrm{mmol}$ litre -1 , and the patient is not oliguric, subsequent fluids should have $40 \mathrm{mmol}$ litre-1 of potassium chloride. Adequate fluid, potassium and insulin therapy will resolve the acidosis in DKA, but there may be disturbances of other electrolytes including bicarbonate, sodium, and phosphate. Generally, these electrolyte imbalances improve as the DKA is treated effectively. Typical fluid and electrolyte deficits are summarized in Table 2.

Table 2

\begin{tabular}{|l|l|}
\hline \multicolumn{2}{|c|}{ Typical fluid and electrolyte deficits in adults with DKA } \\
\hline Water $100 \mathrm{ml} \mathrm{kg}-1$ \\
\hline Sodium $\quad 7-10 \mathrm{mml} \mathrm{kg}-1$ \\
\hline Chloride & $3-5 \mathrm{mmol} \mathrm{kg}-1$ \\
\hline Potassium $\quad 3-5 \mathrm{mmol} \mathrm{kg}-1$ \\
\hline
\end{tabular}

\section{Conclusion}

Pathophysiology-driven DKA management is complex and requires careful selection of approaches aimed at restoring deficiencies in insulin, fluids, and electrolytes. Available clinical practice recommendations and guidelines offer solid foundations for achieving successful DKA resolution. However, we advise that individualized decisions should be made, as DKA patients may have unique clinical and biochemical characteristics. Safe strategies to restore volume deficit and replace insulin should be implemented, with frequent evaluations of the patient's status aimed at monitoring for DKA resolution and avoiding potential complications. Recent studies showing clinical benefits and safety of subcutaneous insulin administration in patients with mild DKA and utility of protocoldriven care offer new pathways to reducing the cost of DKA care while maintaining quality of clinical outcomes. Also, resources should be directed toward the education of primary care providers and patients and their families so that they can identify signs and symptoms of uncontrolled diabetes earlier. With the increasing focus on health disparities, access to medical care is a major focus in determining better care in diabetes, which would ultimately contribute to decreasing the occurrence of hyperglycemic crises of diabetes.

\section{References}

1. Gosmanov AR, Wall BM. Diabetic ketoacidosis. In: Bope ET, Kellerman RD, editors. Conn's Current Therapy. Philadelphia, PA: Elsevier Saunders; 2014. 2014. pp. 710-713.

3. Kitabchi AE, Umpierrez GE, Miles JM, Fisher JN. Hyperglycemic crises in adult patients with diabetes. Diabetes Care. 2009;32(7):1335-1343.

4. Kitabchi AE, Nyenwe EA. Hyperglycemic crises in diabetes mellitus: diabetic ketoacidosis and hyperglycemic hyperosmolar state. Endocrinol Metab Clin North Am. 2006;35(4):725-751.

5. Randall L, Begovic J, Hudson $M$, et al. Recurrent diabetic ketoacidosis in inner-city minority patients: behavioral, socioeconomic, and psychosocial factors. Diabetes Care. 2011;34(9):1891-1896.

6. Umpierrez GE, Smiley D, Kitabchi AE. Narrative review: ketosisprone type 2 diabetes mellitus. Ann Intern Med. 2006;144(5):350 357.

7. Gosmanov AR, Umpierrez GE, Karabell AH, Cuervo R, Thomason DB. Impaired expression and insulin-stimulated phosphorylation of Akt-2 in muscle of obese patients with atypical diabetes. Am J Physiol Endocrinol Metab. 2004;287(1):E8-E15.

8. Kitabchi AE, Umpierrez GE, Murphy MB, Kreisberg RA. Hyperglycemic crises in adult patients with diabetes: a consensus statement from the American Diabetes Association. Diabetes Care. 2006;29(12):2739-2748.

9. Sheikh-Ali M, Karon BS, Basu A, et al. Can serum betahydroxybutyrate be used to diagnose diabetic ketoacidosis? Diabetes Care. 2008;31(4):643-647.

10. Nyenwe EA, Kitabchi AE. Evidence-based management of hyperglycemic emergencies in diabetes mellitus. Diabetes Res Clin Pract. 2011;94(3):340-351.

11. Caputo DG, Villarejo F, Valle GB, Díaz Aguiar P, Apezteguia CJ. Hydration in diabetic ketoacidosis. What is the effect of the infusion rate? Medicina (B Aires) 1997;57(1):15-20. Spanish.

12. Basnet S, Venepalli PK, Andoh J, Verhulst S, Koirala J. Effect of normal saline and half normal saline on serum electrolytes during recovery phase of diabetic ketoacidosis. J Intensive Care Med. 2014;29(1):38-42.

13. Fisher JN, Shahshahani MN, Kitabchi AE. Diabetic ketoacidosis: low-dose insulin therapy by various routes. $N$ Engl J Med. 1977;297(5):238-241.

14. Kitabchi AE, Umpierrez GE, Fisher JN, Murphy MB, Stentz FB. Thirty years of personal experience in hyperglycemic crises: diabetic ketoacidosis and hyperglycemic hyperosmolar state. J Clin Endocrinol Metab. 2008;93(5):1541-1552.

15. Kitabchi AE, Murphy MB, Spencer J, Matteri R, Karas J. Is a priming dose of insulin necessary in a low-dose insulin protocol for the treatment of diabetic ketoacidosis? Diabetes Care. 2008;31(11):2081-2085.

16. Goyal N, Miller JB, Sankey SS, Mossallam U. Utility of initial bolus insulin in the treatment of diabetic ketoacidosis. J Emerg Med. 2010;38(4):422-427.

17. Rosenthal NR, Barrett EJ. An assessment of insulin action in hyperosmolar hyperglycemic nonketotic diabetic patients. J Clin Endocrinol Metab. 1985;60(3):607-610.

18. Maletkovic J, Drexler A. Diabetic ketoacidosis and hyperglycemic hyperosmolar state. Endocrinol Metab Clin North Am. 2013;42(4):677-695.

19. Umpierrez GE, Cuervo R, Karabell A, Latif K, Freire AX, Kitabchi AE. Treatment of diabetic ketoacidosis with subcutaneous insulin aspart. Diabetes Care. 2004;27(8):1873-1878.

20. Umpierrez GE, Latif K, Stoever J, et al. Efficacy of subcutaneous insulin lispro versus continuous intravenous regular insulin for the treatment of patients with diabetic ketoacidosis. Am J Med. 2004;117(5):291-296.

21. Ersöz HO, Ukinc K, Köse M, et al. Subcutaneous lispro and intravenous regular insulin treatments are equally effective and safe for the treatment of mild and moderate diabetic ketoacidosis in adult patients. Int J Clin Pract. 2006;60(4):429-433. 
22. Shen T, Braude S. Changes in serum phosphate during treatment of diabetic ketoacidosis: predictive significance of severity of acidosis on presentation. Int Med J. 2012;42(12):1347-1350.

23. Fisher JN, Kitabchi AE. A randomized study of phosphate therapy in the treatment of diabetic ketoacidosis. J Clin Endocrinol Metab. 1983;57(1):177-180.

24. Winter RJ, Harris CJ, Phillips LS, Green OC. Diabetic ketoacidosis. Induction of hypocalcemia and hypomagnesemia by phosphate therapy. Am J Med. 1979;67(5):897-900.
25. Foley RN, Collins AJ. End-stage renal disease in the United States: an update from the United States Renal Data System. J Am Soc Nephrol. 2007;18(10):2644-2648.

26. Kovesdy CP, Park JC, Kalantar-Zadeh K. Glycemic control and burnt-out diabetes in ESRD. Semin Dial. 2010;23(2):148-156.

27. Tzamaloukas AH, Ing TS, Siamopoulos KC, et al. Body fluid abnormalities in severe hyperglycemia in patients on chronic dialysis: review of published reports. J Diabetes Complications. 2008;22(1):29-37. 